\title{
The black church as the timeless witness to change and paradigm shifts posed by the Fourth Industrial Revolution
}

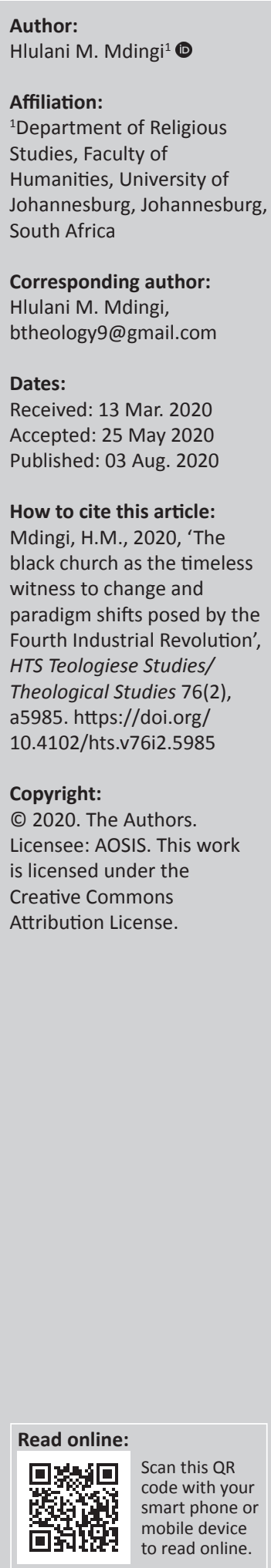

The current technological and scientific developments of the Fourth Industrial Revolution (4IR) signal great leaps in human intellect and creativity. At the crossroad of great steps into the future, a future that will be determined by science and innovation, the smeared bond between theology and science recoils upon theological consideration of human intellect. Black liberation theology has stressed a change in paradigm, which takes oppression, class and intellect seriously. This research seeks to elaborate that a general acceptance of human intellect and science tends to ignore that modern-day science is part of Western civilisation. The Western world view remains dominant in the world. It will be argued that while the 4IR is important, the intellect, politics, economics and need for a 4IR, however, remain synonymous with the need of the West to 'civilise' the world. Institutions such as the World Economic Forum are Western institutions and still represent the goals of Western civilisation. This article argues that great leaps in science must be measured by the Christian church's commitment to eschatology and a building of an egalitarian society on earth. The article seeks to explore if the notion of a black church can be instrumental in the 4IR for focusing on the human condition and humanity of the oppressed in Africa and Latin America. The article argues that the church's role is to witness great change in society and it must be prepared to actively respond to great societal change posed by the 4IR.

Contribution: This article focuses on theology and the Fourth Industrial Revolution, as such, cutting across disciplines. This allows engagements to occur in all disciplines, proving the relevance of theology today. The contribution of this research is its emphasis on the role of theology within techno-political development.

Keywords: 4IR; Intellect; Black church; Technology; AI; Black theology.

\section{Introduction: Political and epistemological clarification}

The subject of scientific inquiry and technological advancement that characterises the Fourth Industrial Revolution (4IR) is not foreign to theology and in the history of the church. ${ }^{1}$ The scientific and philosophical debates that occurred during the enlightenment between science and the church resulted in two approaches to understand reality: (1) a theistic world view with teleological acceptance of nature and intelligent design and (2) the material reading of the world without the need for a transcendent deity (Barret 2000; Gillespie 2008). As it appears, 4IR has no metaphysical inclination towards the nature of the world and human beings. ${ }^{2}$ Perhaps, the philosophical undertones and epistemology that drive towards the acceptance of materialism in relation to the nature of reality and that are found in materialism are accepted as the school of thought that defines reality today.

The philosophical rejection of a metaphysical understanding of the world is visible in the impulse of human beings beginning to recreate, replicate and restructure biological systems. God is dead, not in the Nietzschean sense of morals and values but in application of redefining the world and all in it, a quest of 4IR. The most important aspects of 4IR, such as biotechnology, digitisation and transhumanism, and more importantly, the role of artificial intelligence (AI) and robotics, come in a direct confrontation with the more fundamental aspects of theology, which relates to human

1.In this research, church has two connotations: (1) it refers to a more 'catholic' vision of faith. (2) The broad or catholic definition of the church is replaced by a black church because of the role Western Christianity has played in oppression.

2.See John Lennox's talk on Al held on 09 October 2018 at Zacharias Institute in Alpharetta, GA. 
beings, nature and God. Whilst they may be good aspects of $4 \mathrm{IR}$, the more important, fundamental and dangerous aspects of it require the church to be on guard.

For black liberation theology, the theological and epistemological underpinnings of the material reading of the world become important for politics, economics and an expression of faith of those who have been marginalised in the world. Mabasa (1984:56-57) remarked in an address to the Forum of National Unity that ' $r$ ]evolution cannot be imported nor exported'. Revolutions, including scientific revolutions, are aligned with national and continental demands of a particular society. Human solidarity for progress, oppression and intellect are ideals that can be shared across civilisations and societies. However, like previous revolutions, often occurring within the technopolitical context of the West, it points to a revolution that is imported and imposed through an institution such as the World Economic Forum to affect the world. In short, technology has gone against the grain of political ideology and philosophy that wrestle with the existential reality and datum of a particular people and context, especially when liberation is a prerogative. As such, 4IR is not just viewed from a vantage point of great leaps in human intellect. Central to the argument of this research is to bring attention to the fact that definitions of human intellect and progress are woven by appendages of geopolitical contexts, which draw from the historical contestation of who is human. Africa and Latin America are still attempting to express its humanity through the desire to be liberated and self-authenticated. Technology is useful for humanity; however, it is not devoid of cultural influences. This research does not negate the use of Western technology for black people but instead seeks to move black people's technological development within their own prerogatives of liberation.

\section{Human intellect and Africa and Latin America}

Human intellect, which has been bequeathed by nature or God, should not lead humanity to a collective hallucination of reality that will result in devastation. In the Black World, 4IR should not be imported or at least not in its entirety. Artificial intelligence, which is fundamental for 4IR, requires serious scrutiny as it will influence humanity and the world. Tergmark ${ }^{3}$ noted that in the area of AI 'it might be the greatest invention for humanity or the biggest mistake in human history'. As such, any form of intelligence or intellect must be properly guided. Theology suggests that human intellect is bequeathed to us by the creator. However, the evolution and revolution occurring through $4 \mathrm{IR}$ are unparalleled. This is an evolution not decided by natural process; instead, it is an evolution guided by human intellect and the concentration of global political power. At a biological level, nature sees an evolution beyond biological systems - a blending of metaphysics or ontology and nature. This $[r]$ evolution, 4 IR, is 3. Max Tergmark is a theoretical physicist at the Massachusetts Institute of Technology
(MIT). He discussed Artificial Intelligence (AI) in relation to Human 3.0 at MIT (MIT). He discussed
(see Fridman 2018). ontological and influences biological, architectural, molecular and atomic systems. Schwab (2016) argues:

The word 'revolution' denotes abrupt and radical change. Revolutions have occurred throughout history when new technologies and novel ways of perceiving the world trigger a profound change in economic systems and social structures. Given that history is used as a frame of reference, the abruptness of these changes may take years to unfold. (p. 11)

Schwab (2016:8) further argues that ' $[t]$ he changes are so profound that, from the perspective of human history, there has never been a time of greater promise or potential peril'. The promise and peril noted by Schwab make black liberation theology the notion of a black church and position the church to bear witness to a possible beginning or end. The church has witnessed the historical unfolding of the modern world for two millennia. The ability of human intellect, interpretive aesthetics and expressions, such as language and symbols of mathematics, is galvanised to give a human language to natural phenomena. The point of argument highlights the fact that somehow intellect has been able to replicate biological systems through arrangement of natural properties, which proves to be a continual and communal blending of humans' consciousness (intellect) in re-arranging the world. Disciplines of humanities and the sciences have long been entangled, even beyond the debate of religion and science. The relationship between intellect and nature is proved in architectural structures that see a new birthing of humanity and nature by science and technology and science becomes the midwife moving humanity from biological and dialectical relationship of human and 'Mother Nature to mothering nature' ${ }^{4}$ The leap to mothering nature raises fundamental epistemological, political and theological concerns for the church and its doctrines. Oxman (2016) further argues that:

If 'nature' is described as 'anything that supports life', and if life 'cannot be sustained without culture', the two belief systems collapse into singularity. In this singularity, Nature claims the infrastructure of civilization and, equally so, culture now enables the design of Nature herself. (p. 7)

There seems to be an epistemological crisis to scientific discovery. The singularity that Oxman (2016) refers to is an ideal that already existed in other non-European cultures not plagued by the slaughtering effect of the Enlightenment's rationalism, deductionand empiricism. Theinterconnectedness of all reality has always been cherished by beliefs systems (even Judeo-Christianity) that acknowledge God, human and nature. It seems plausible, considering Oxman (2016), to note that 4IR discoveries are late conceptions for the wholeness of life emerging from the West. Their sudden interest in the connection or connecting of nature and reality raises fear for the real intents of 4IR. The church must become a timeless witness even at moments of great scientific revolutions. Furthermore, it raises the hermeneutical and epistemological ambience for liberation theology and the notion of the black church in engaging the world. ${ }^{5}$

4.See Neri Oxman TED Talks on Design at the Intersection of Technology and Biology.

$5 . I$ have not come across any material on black theology and 4IR. 


\section{What is the Fourth Industrial Revolution?}

The 4IR has been announced as development that will change human experience (see Schwab 2016). It draws from the three preceding industrial revolutions, which produced steam trains and printing press, electricity and the technological era, and these revolutions had little emphasis on the human being. Bloem et al. (2014) assert that:

The Industrial Revolution is a concept and a development that has fundamentally changed our society and economy. The term 'development' may seem to indicate some tardiness in the context of a 'revolution', which really signifies a rapid and fundamental change, but there is no doubt that major alterations occurred within a relatively short period. (p. 11)

Bloem et al. (2014:11) further note that the second and third industrial revolutions of the 20th century are usually typified by mass production, the conveyor belt and digital automation. Ferrari (2017:S2626) pointed out that the Second Industrial Revolution focused on mass production because of steam power and the Third Industrial Revolution was predominantly about electronics and information technology.

Unlike the previous revolutions, 4IR is based on AI, Internet of things (IoT), three-dimensional (3D) printing and genetic engineering (see Prisecaru 2016:58). The 4IR seems to be evolutionary in its unfolding as it continues from the gains that have come to classify the modern period and especially with regard to human intellect and moulding the world to a desired reality. It gives rise to scientific achievement such as robotics, nanotechnology, transport, IoT, virtual reality, biotech, blockchain, 3D and four-dimensional (4D) printing. Schwab (2016:31) asserts that ' $t$ the scale and breadth of the unfolding technological revolution will usher in economic, social and cultural changes of such phenomenal proportions that they are almost impossible to envisage'. What Schwab asserts is true as 4IR entails serious expectation of the future, such as the future of energy, which will be characterised by new solar energy and wind energy to introduce fossil-free energy (see Van Hooijdonk 2018).

The Fourth Industrial Revolution includes the role of AI in the future. Artificial intelligence and biotechnology seem to be the most eyebrow-raising topics of 4IR for the church because of their connotation to human beings in relation to intellect and genes without the role of a creator. There are two forms of AI, namely, strong AI and weak AI. Strong AI refers to machines having the ability to think as humans. Weak AI refers to machines being made to look as if they are intelligent (Kumar \& Thakur 2012:57). The roots of AI are in the fields of philosophy, logic or mathematics, computation, psychology or cognitive science and biology or neuroscience (Kumar \& Thakur 2012:58). Kumar and Thakur (2012:58) assert that ' $[a]$ n important goal of AI research is to devise machines to perform various tasks which normally require human intelligence'. The bond of biology and AI rests on the role of intelligence in the human brain. This bond is expressed in artificial neural networks that use AI as an application, which mimics human intellect. Kumar and Thakur (2012) assert that:

Generalization is the only ability that makes ANNs so powerful tool. How the human brain works, it learns to realise patterns and remembers them. Similarly, the neural networks developed have the ability to learn patterns and remember. (pp. 58-59)

Learning methods in neural networks are divided into three sections: (1) supervised learning that requires an external teacher, (2) unsupervised learning that requires an external teacher because of links to self-organisation and (3) reinforced learning that is set up as learning with a critic rather than a teacher (Kumar \& Thakur 2012:59). Part of AI is the use of a brain-computer interface, which allows a human to control a robot with his or her brain (Kumar \& Thakur 2012:60). Furthermore, robotics is a central feature for AI. According to Kumar and Thakur (2012):

Robotics is one field within artificial intelligence. The term 'artificial intelligence' is defined as systems that combine sophisticated hardware and software with elaborate databases and knowledge-based processing models to demonstrate characteristics of effective human decision making. (p. 65)

Kumar and Thakur (2012) further give insights into the variation in the strands of $\mathrm{AI}$ and their relation to autonomous robotics:

Traditional Robotics uses Artificial Intelligence planning techniques to program robot behaviors and works toward robots as technical devices that have to be developed and controlled by a human engineer. The Autonomous Robotics approach suggests that robots could develop and control themselves autonomously. These robots are able to adapt to both uncertain and incomplete information in constantly changing environments. It lets a simulated evolution process develop adaptive robots. (p. 65)

The importance of reflecting on $\mathrm{AI}$ is fundamental in discussions about human intellect. Artificial intelligence as proposed by 4IR has something to say about human beings and the human condition (Tergmak warning). Prisecaru (2016:57) notes that the previous revolutions resulted in change from a feudal society to an industrial and capitalist society and are leading to post-industrial societies without physical labour and mental efforts. Those revolutions did very little in uplifting the human condition because of profit. The discussions about the continuation of the third revolution into the fourth revolution are best expressed in Rifkin's (2008:4-7) expression of the goals of the Third Industrial Revolution (see Prisecaru 2016:57): (1) the shift from fossil fuel to renewables, (2) transforming the building stock to green microplants, (3) the use of hydrogen in all buildings, (4) the technology of the Internet to transform electricity network and (5) the ability to transform transport systems to using electricity. The Fourth Industrial Revolution is at a vintage point because of the nexus and connection caused by the IoT. Prisecaru (2016) asserts that:

The so-called Internet of Things will transform the world enhancing the labor productivity, making transport more 
efficient diminishing the energy needs, supporting dealing more effectively with climate change, as due to electronic means offered by Internet one may usually send and receive data from other devices or from individuals. (p. 58)

Prisecaru's (2016) analysis of human obsolescence in the workplace suggests a limit for humans despite the already existing low wage of the poor. Rifkin's (2008:4-7) proposal of renewables reflects the effects of a profit-driven society that has contributed to the destruction of the ecosystem - creation. These points of human value and nature become cardinal points for the church witness, especially considering the psychological, economic and cultural shift that profit-driven markets are capable of doing in the world. The Christian church must be rooted in creation and must have the moral responsibility of being Imago Dei.

Another aspect of the 4IR is its influence of design and nature. ${ }^{6}$ Ferrari (2017) states that design has transformed based on the environment or the influence of natural surroundings. Ferrari (2017:S2625) notes various periods that entail the relationship between human, nature and design. He points to the periods of Homo Faber (the maker of things in the Neolithic Age), humans as machine creators and the age of the Homo Gubernator (humans in an age of cybernetics, high technology and in the age of complexity). The insights from Ferrari (2017) point to the role of humans in development, and advancement decided upon by ecological prerogatives and existential needs. Oxman (2010) asserts that:

Nature is demonstrably sustainable. Her challenges have been resolved over eons with enduring solutions with maximal performance using minimal resources. Unsurprisingly, nature's inventions have for all time prompted human achievements and have led to the creation of exceedingly effective materials and structures, as well as methods, tools, mechanisms and systems by which to design them. (p. 81)

The Edenic setting is explicit in Oxman's view of the intervention and interconnection of nature and human creativity that sees human beings augment nature to work side by side with humans. The creative aspect in human beings has led humans to develop tools that could assist them in design. It is worth noting that despite the role of material and applied sciences in 4IR, the role of the mind, whether by human design or the mind behind creation, remains inextricable from creativity, creation and humanity. This point is important for metaphysical reflection on nature and the view of humans as Imago Dei. If natural selection or God allows human development to flourish on the basis of the environment, the Black World cannot ignore its own impulse for development. More so, the indigenous religions have moulded reality within the confines of a culture and as a testimony to creation. Daneel (1999:218) noted that Africans have always seen themselves as earthkeepers, and the earth becomes the sacramental table to African spirituality. This

6.Theologically, this approach ignites the parabolic Edenic setting of Genesis 1-3, with human beings given the responsibility of tilling the land. The role of design in $4 I R$ is human beings given the responsibility of tilling the land. The role of design in $4 I R$ is
important for reflection in the black world, especially, with regard to the land important for reflection in the black world, especially, with regard
question, the link between indigenous religion and the environment. position of the metaphysical, in the form of thought behind creation and design, becomes extremely important for epistemological reasons.

Ferrari (2017:S2626) notes that Schwab (2016:12, 156) has described 4IR as a fusion of technology cutting across disciplines and blurring the lines between physical, digital and biological spheres. Epistemologically, this point is important in relation to the definition of reality that goes beyond the abstract - though linked by ontological leanings to abstraction - forcing perceptual and existential change. The West, at least through 4IR, is seemingly late in connecting reality or understanding the importance of a multidisciplinary ${ }^{7}$ approach. The Fourth Industrial Revolution is Western, just as previous industrial revolutions that occurred in Europe and America and for the benefit of superpowers. As such, the design of primitive humans extends the abstract connection to form, reality and needs. Doubrovski et al. (2015) assert that:

Form, structure, material, and function are intimately intertwined in Nature, complementing and relying upon each other. The evolution of both form and material occurs in tandem, informed by their environment and enabled by the process of material fabrication. (p. 3)

Doubrovski et al.'s (2015) view demonstrates the intersectionality of what is defined as nature, and by extension defines what is conceived as reality and natural processes. The change of epistemology is expressed by Oxman (2016:2) when she stated, '[a]t the dawn of the new millennium, the meme "antidisciplinary" appeared, yanking us out of Aristotle's shadow and into a new "Age of Entanglement"'. This entanglement, which is recent in Europe, has long been expressed in the indigenous people's natural theology and science (Ani 1994:66-67). If 4IR is true, then a part of it had long been anticipated in the world views of the black people of the world. People bound reality together without distinct or distant pockets of reality and truth (Ani 1994:67). The fact that nature has been at the core of aspects of belief systems suggests that Schwab (2018:12, $156)$ is late - the blurring lines across disciplines have been pervasive outside of Europe and Western civilisation. The interconnection of things is correctly expressed by $4 \mathrm{IR}$ although there should be anxiety about the culture to lead the world into this new dawn. This point then draws the discussion around 4IR to a geopolitical context of the West. Maynard (2015) noting a new framework being promoted in Germany and adopted in other countries asserts that:

This technological convergence is increasingly being referred to as the 'fourth industrial revolution', and like its predecessors, it promises to transform the ways we live and the environments we live in. (p. 1005)

Maynard (2015) located this shift in Germany and gives hermeneutical and epistemological insights that make the discussion of 4IR a cultural prerogative of a certain civilisation

7.The use of multidisciplinary here is meant to convey the interrelatedness of al things and knowledge systems. An approach that an African world view holds close to a definition of reality, knowledge and religion (see Marimba Ani Yurugu 67-68). 
seeking to perfect technological know-how (Biko 1978:51). It is that cultural prerogative that liberation theology must safeguard against.

\section{Why theology is important for this discussion}

Gillespie (2008) provides theological roots of modernity because science and technology are the product of modernity. Modernity extends the projection of humanity and makes humanity cast out or postpone their conception of the end of day. Gillespie (2008:2) argues that modernity is a description of oneself in terms of time, one's own being, freedom and interaction with the world. He argues that the advancement of science and technology in relation to the modern world is closely linked to the scientific revolution. Barret (2000) notes that Greek natural philosophy and science brought challenges to the church authority and Aristotle. Barret (2000:4) gives historical phases of natural science, scientific century (14th century), Copernicus' heliocentricity (1543), Kepler's planetary motion (1596), Galileo's telescope (1604) and Newton's Principia Mathematica (1687). In philosophy, it was Descartes who stressed about deductive thought and Francis Bacon who emphasised the use of data. This period identified the role of human reason (the mind) and consciousness, especially in demonstrating the consciousness of matter. Gillespie (2008:4) notes that some Christian thinkers thought about modernity as 'standing on a threshold of eternity'. The human experience, which occurs through the channel of time, validates the fundamental difference between antiquity and the move to modernity, and Gillespie notes that the early generation of modernists such as Bacon saw the ideas of the Greeks as incomparable to his age, which was largely because of the human experience. Gillespie (2008) commenting on Bacon's view argues that:

What underlay this changed evaluation of antiquity was not merely a new notion of knowledge but also a new notion of time not as circular and finite but as linear and infinite. Change was pictured as a continuous natural process that free human beings could master and control through the application of proper scientific method. In this way they could become masters and possessors of nature and thereby produce a hospitable world for themselves. (p. 5)

The role of technology and science within the human experience, which sought to produce a hospitable world, has political implication. Marx's analysis of revolution was not the rejection of the great strides of human intellect demonstrated in the development of technology and science but on the gains of such developments shared by all (Gillespie 2008:7). This sharing of the gains has been impossible and raises questions for the future. Theology, although it has been ignored in the discussion of $4 \mathrm{IR}$, is important to the rise of modernity. Barret (2000:10-12) noted that science, physics in particular, has revealed accurate measurements through experiments; it has proved the usefulness of mathematics. However, science and mathematics are limited. Barret (2000) asserts that:
In contrast, theology has a much wider scope. Its basic task is to seek the deepest level of understanding of whatever is the entire range of reality, taking into account the insights and knowledge derived from other disciplines. Therefore theology is encouraged to be an integrating discipline, drawing upon wide-ranging insights in the formulation of a metaphysical theory of all that is. Some physicists say confidently that a 'theory of everything' will be discovered one day, but it is to theology, not theoretical physics, that one should look for a genuine theory of everything, a meta-narrative which brings together the unfolding worldpicture of science and the paradoxes of human experience and understanding. (p. 11)

One could argue that theology is important for its metaphysical or theistic emphasis on reality although (black) liberation theology proposes an existential activity of this metaphysical deity. Gillespie (2008:14) notes that the vigour and drive towards a scientific world view are because of this metaphysical position of theology and the church. He argues (Gillespie 2008) that:

The epochal question that gave birth to the modern age arose out of metaphysical/theological crisis within Christianity about the nature of God and thus the nature of being. This crisis was most evident as the nominalist revolution against scholasticism. This revolution in thought, however, was itself a reflection of a deeper transformation in the experience of existence as such. Scholastics in the High Middle Ages were ontologically realist, that is to say, they believed in the real existence of universals, or to put the matter another way, they experienced the world as the instantiation of the categories of divine reason. They experienced, believed in, and asserted the ultimate reality not of particular things but of universals, and they articulated this experience in a syllogistic logic that was perceived to correspond to or reflect divine reason. Creation itself was the embodiment of this reason, and man, as the rational animal and imago dei, stood at the pinnacle of this creation, guided by a natural telos and a divinely revealed supernatural goal. (p. 14)

The metaphysical influence on the modern scientific drive took seriously the concept of God and creation. Christian theology becomes important especially because the 4IR is an evolutional process that is guided not only by a divine mind or authority but also by human intellect, politics and scientific and mathematical tools. If modernity occurred within the confines of metaphysics, then in the age of the 4IR, God has been replaced as the divine mind or divine reason in the new era of evolution in order for the human mind to be the guiding force for change and development. The divine mind should be the mind of the God of the oppressed, which is a mind that grasps human intellect, greed, deceit and vulnerability to cause harm to the world and other species.

\section{The black church: The ecclesia of disembowelled and disembodied}

The method of describing the notion of a black church notes it as a religious experience of people of African descent. This theological expression links the experiences of Africans in North America and South Africa (see Maimela 2005:29). 
Furthermore, in Africa, Maluleka (2004) noted that theological innovation all stems from what is called African Christianity, which influences the aims of black theology and African theology. The notion of a black church is a religious experience for those denied of human intelligence and those subjected to dehumanisation. The notion of the black church has epistemological, hermeneutical and political concerns of the oppressed and black people. Boesak (2004:56) noted that black theology was bringing a message of the gospel to our people and in light of their situation. The role of bringing the gospel to the oppressed remains even in 4IR to stress the demand of the oppressed in great technological advancement.

The black church is central to the questions raised concerning human intellect and technology, especially with reference to 4IR. The black church can be described as the black religious experience shared by black people across denominational lines, in the continent and diaspora. The black church transcends church buildings and becomes a religious experience of those deemed as subhuman and thus enslaved for the enterprise of servitude to white and Western socioeconomic, technological and cultural expansion. The role of a black church expresses liberation as central to articulation of faith and belief in a transcendent God, who is revealed intellectually, politically and existentially to black Christianity. Billingsley (1999:7) notes the historical African American black church, in the person of the black preacher: ' $[t]$ he preacher is the most unique personality developed by the Negro on American soil. A leader, a politician, an orator, a boss, an intriguer an idealist'.

The role of the black preacher or theologian in the 21st century should be modelled around the Negro preacher who is the 'idealist, politician and leader' in order to mould the spiritual and intellectual aspects of believers and context towards an egalitarian conception of freedom rooted in an intervening and community-based God, while protecting the intellect of its believers from carelessness and naivetés that are possible in blind faith and acceptance of 4IR. This carelessness and naivetés will be demonstrated by the gullibility of black people and the oppressed in believing that 4IR has their aspiration at heart. When South African leaders visited Davos during 2016-2020 (see World Economic Forum 2016), they were presented a picture of the $4 \mathrm{IR}$ as a given, without critique, to solve their historical problems as a society. However, there are good things that 4IR provides, for instance, in education (Xing \& Marwala 2017), which should not ignore the human condition.

West (1999:62), in the American context, argues that ' $[b]$ lack people became Christians for intellectual, existential and political reasons'. If this can be argued to also be the case elsewhere in the world, black Christian encounter with the world and even in great leaps into the sciences requires clarity of their humanity, their intellect that allows the Black World, Africa and Latin America to decide on their sovereignty, future and aspirations. West (1999:70) notes that the humanity and equality of black people as humans are a recent discovery in the modern West and in sciences, and it is problematic as it underlines factors to be considered with regard to intellectual capacity.

Black liberation theology should understand that great leaps in sciences, especially engineered by advanced countries, pose a threat to human capacity. Technological progress must be judged in light of constantly evolving white supremacy (West 1999:70), with awareness that the oppressed do not remain servile to the dictates of Western intellectual and political needs. The Fourth Industrial Revolution, whilst seeking to advance humanity to a new reality of human existence, must seriously consider the effect of 400 years of oppression in underdeveloped countries, especially as an intellectual setback. The denial of the humanity of others includes the denial of their intellect. Great advancement hangs at the threshold of multiple possibilities. Averill (1974) explains the threshold as follows:

Existence 'on the boundary' - awareness at once of the stubbornness and the fragility of human life, of the possibility of an expanded humanness and humaneness beyond all our dreams, and yet of the possibility, too, of a dehumanization beyond all our nightmares - this boundary-line situation is probably the most pervasive themes of our present culture. (p. 13)

Averill's (1974) analysis provides the constant role that the notion of black church should continue to play, which is a deep commitment to the value of human fragility and the importance of humaneness, which should not be replaced by technology. The dispute of the 16th-century Europe between church and science witnessed a breakaway of those who wanted to make use of human intellect, which was negated by religious dogma. The religious and scientific players were both Western. Through historical processes, both the religious and scientific positions of Western civilisation converged in oppression and world domination. West (1999:63) noted that the black religious experience had and has its own intellectual prerogatives. These prerogatives, namely, liberation and sovereignty, will make black people become their own inventors inspired by their geopolitical context of the Global South (Hlatshwayo 2019:28).

Advanced technological development poses serious existential anxieties to blackness, black spirituality, justice, human condition and liberation. The dimension of Western science and black liberation shares a historical connection. The West sees scientific advancement as human progression. However, the black experience seems to see it as armoury of the Western domination of the world. The black experience creates the viewpoint that ideas and human beings are set against this armoury, veiled in scientific development and progress. Tiro (1972) validates this point by pointing out that Western weaponry or technology cannot prohibit liberation.

Tiro (1972) emphasised education and ideas operating within the political paradigm. Education cannot be isolated from political and economic progress, especially in the Black World or Africa and Latin America. Tiro also highlights strong themes that run deep in the black liberation struggle, 
black consciousness, black radical tradition and black theology, which are greatly against technological progress, usually demonstrated in armoury. Technology as used by the West has undermined being human. Biko (1978:51) points out, ' $[w]$ e reject the power based society of the Westerner that seeks to be ever concerned with perfecting their technological know-how while losing out on their spiritual dimension'. Throughout the prospects of black liberation, science, especially technology, has been viewed with scrutiny. There is a distrust concerning the real intents of Western civilisation and technology. Malcolm's speech The Ballot or the Bullet (1964) highlights distrust and willingness to fight against the technological odds. Mabasa (1983) argues that:

In our country, Black people are faced with the task of having to defeat an enemy armed to the teeth with destructive weapons of modern technology. We know that the outcome of our battle will not be decided by technology but by the will of our people. The final outcome will not be decided by the massive accumulation of weapons, however genocidal, but by the local and historical consciousness of the masses, the peoples involved and determined to resist the violence with whatever means available to defend themselves in an implacable contest. (pp. 136-137).

Black liberation, which often stresses humans above technology, reflects the irreconcilable reality of the oppressed with Western technology. Moreover, it highlights the dangers of science and its progress that is problematic when all forms of injustices against black people and the oppressed have not been equitably resolved. West (1999:115) notes how globalisation, which praises science, biology and technology, makes the effects of racism outdated.

West (1999:115) notes that race has been made irrelevant in the modern and materialistic context, contrary to the deep theistic vision of black theology and liberation. The fact that scientific and technological innovations and biology through globalisation make race irrelevant becomes a point of deep meditation and reflection for the black church. Modernity brought out the worst in human beings (Gillespie 2008:7) that those affected by the modern project usually are the downtrodden who are not even considered fully human by those who are already human and with multiple strands of power. Gillespie notes that Heidegger saw an ontological deconstruction of Western rationalism as a prerogative of this age in order to usher in a new beginning. He notes Heidegger's view of an ontological deconstruction and Nietzsche's pronunciation of the death of God, which is the death of Western Christian values, and he believes in the new openness of the world (Gillespie 2008:12-23). Whilst war and various forms of injustices can occur in the transformative pattern of the world, the room for possibility is open. Nietzsche and Heidegger represent the philosophical strand of thought away from classical metaphysics.

The universe, through the scientific revolution and the emergence of mechanical philosophy, proved to be a mathematical design and mathematically precise mechanism in the form of the universe. This approach in the sciences rejected and dispelled the metaphysical and the spirit-filled conception of the universe as an organism (Barret 2000). Whether there occurs an ontological destruction or change of values according to Heidegger and Nietzsche, the fact that these developments should occur in the West reflects the 'unique' position Western civilisation has. Western civilisation determines its changes contrary to the demands of Western civilisation and globalisations imposed on those it lords over. Barret (2000:16-21) provides a serious reflection and question on the scientific revolution. Barret asks why the scientific revolution did not occur in China, India and in the Islamic world because these three nations had advanced mathematics, science, astronomy and so on. Barret, however, gives insights into why this scientific revolution occurred in Europe and bases his argument on the fact that these three nations had a deep metaphysical doctrine embedded in their belief about the world and reality. Western civilisation easily rejects the metaphysical approach as intrinsic to existence and intellect (Ani 1994; Biko 1978). This point is important in understanding why Western civilisation through its advances easily tramples on the belief systems of those it oppresses.

The rise of scientific advancement should not ignore the fact that the poor are bound in their existence by a deep sense of vulnerability to existing systems dictated by the will of the powerful. The black church, which has its roots in invisibility and namelessness, becomes the openness for possibilities, which guides the intellectual achievements of the poor and the metaphysical presence that permeate the world. For black Christianity, with serious consideration of black dehumanisation, metaphysical conceptions of God re-ignite an ethical system based on something beyond the physiological self. The rise of applied and materials sciences should be kept in check by the intellectual and political strivings of the black church as the ambience of human expression and an encounter with the God of the oppressed. This ecclesiastical approach of the black church should be bound to a continual critique of humans' selfdestruction or the destruction of others in the world, whilst expressing the constant anxiety and worry that scientific achievements have on the oppressed.

Scientific advancements require a religious and moral position, more so, because theology through the doctrine of hamartia has emphasised the fallen statue of human beings and the human condition. Human fragility and limitedness require moral agents. A moral standard perceives and conceptualises within science and becomes inseparable from science and guiding the 4IR. Gillespie (2008) asserts:

Faith in the modern project and idea of progress was shattered by the events of all the first of the twentieth century. The First World War in particular revealed that the progressive development of human power was not simply constructive but could also be hideously destructive, and that technical progress was not identical with moral progress or with increasing human well-being. (p. 7)

The idea of world wars and human power is political in its reference because of the superpower of the world that wills 
who lives and dies through technological weapons, economics and poverty. Gillespie (2008:15) has pointed out the replacement of an infinite God with a powerful God favoured by the nominalist. As such, a link can be drawn between the God of power and human power in the 21st century. The idea of a powerful God can serve the oppressed through relating the power of God in relation to liberation. That powerful God within the black experience transmits human love in the black church. Power transformed into love becomes a guiding force for liberation and should stimulate anew conceptions of the formulation of human intellect and science.

There is a great benefit, at least if some part of $4 \mathrm{IR}$ is seen as self-critique of the West, especially around the ecological crisis that affects the world because of profit and dehumanisation. Rifkin (2012:8-10) has lamented about the effects of fossil fuels on earth. Rifkin (2008:2) notes that there is a need for a different economic narrative that will lead the world into a new direction of renewed energy and use of technology, blending it with the importance of material ecology, which would cast off the burden of previous revolutions that detached the environment from the design of architecture (Oxman 2013). Hensel and Menges (2006:61-64) have argued for morphological intelligence, democratic space and sustainable design. Their definition of morphological intelligence relies on nature's own intelligence being part of the creative ingredient in forming infrastructure. Hensel and Menges (2006) assert that:

A remedy may be found in an understanding of architecture as ecology, involving dynamic and varied relations and mutual modulation between material systems, macro-and microenvironmental conditions, and individual and collective inhabitation. (p. 63)

The notion of a black church should be cognisant of the fact raised by Gillespie (2008:42): ' $[m$ ]odernity has two goals - to make man master and possessors of nature and to make human freedom possible'. Unfortunately, nature has been subdued and the freedom of other human beings outside of the West has not been realised. Nature and its humanity have been bundled up as one. For the black church and the churches that saw nature as their sacrament (Daneel 1999:218), it becomes clear that the change in the world is because of existence on earth being a prerogative. Black Christianity accepts cultural fluency, intellectual vitality for Africa and black people to think on their own. The notion of a black church becomes a place of emphasising the value of being human. Hlatshwayo (2019) has been critical of 4IR, especially with regard to its relation with capitalism and replacing of humans by a system that dehumanises human beings in the world.

Ani (1994:29-30) has pointed out that the African world view has similarities with other people who are not of European descent. The role of origin and sacredness is deeply rooted in their conception of truth and reality. Ani (1994:67) argues that ' $[t]$ he definition of European science reflects European consciousness, and the style of thought generated by that consciousness has become ideological'. What Ani points to supports the epistemological, political and existential anxieties that black people and the black church should have concerning great scientific progress proposed by the West. The value of culture and indigenous world views need to be reaffirmed in the scientific project of great leaps of science in the Black World. This affirmation reminds black people, especially through black theology why it is important to continue stressing the value of humans despite technological know-how (Biko 1978:51). For black liberation theology, the role of Jesus is one of a liberator and a symbol of African metaphysics, which should inform the role of the divine and human in our sciences. Ani (1994) argues:

In the African World-view it is the eternal cycle of life that offers the possibility of transcendence of harmonious interrelationship of wholeness, integration, and organicity. The concept is spiritually satisfying. The European, on the other hand, is perceptually and phenomenally (experientially) limited by his linear conception of reality. There is no link between past, present, and future save a 'casual' link. There is no scared time. History is limited to the secular. Even the most meaningful religious image in the European tradition - that of Christ - is only seen to have value in so far as it can be placed within a 'historic' sequence. It does not have a sacred validity, but a secular one. The dominance of lineal models perhaps helps to account for the spiritual malaise of European societies. (pp. 67-68)

\section{Conclusion}

The Fourth Industrial Revolution is an important technological development; however, it threatens life on earth, as we know it. The notion of the black church accepts great change and participation with that change. However, drawing black use of technology around their prerogatives, black theology is an existential relation of black people to God, with important emphasis on their humanity and fragility. This aspect of Imago Dei and the God of the oppressed is important against a pure materialist development of the world, which might be worse than colonialism, slavery and all forms of injustices visited on the oppressed. Stewart (1999:103-104) noted that the black church represents empowerment, transformation and liberation for black people on various levels, which is a role that it should continue to play. The Fourth Industrial Revolution should not be taken as a given and black liberation theology, the notion of the black church, should safeguard against Africa, Latin America and the Black World being subservient to power through a technological advantage of developed countries.

\section{Acknowledgements}

This article is dedicated to the black church and the current changes which the church will face during the 4IR.

\section{Competing interests}

The author declares that he has no financial or personal relationships that may have inappropriately influenced him in writing this article. 


\section{Author's contributions}

H.M.M. is the sole author of this research article.

\section{Ethical considerations}

This article followed all ethical standards for research without direct contact with human or animal subjects.

\section{Funding information}

This research received no specific grant from any funding agency in the public, commercial or not-for-profit sectors.

\section{Data availability statement}

Data sharing is not applicable to this article as no new data were created or analysed in this study.

\section{Disclaimer}

The views and opinions expressed in this article are those of the author and do not necessarily reflect the official policy or position of any affiliated agency of the author.

\section{References}

Ani, M., 1994, Yurugu an African-centered critique of European cultural thought and behaviour, African World Press Inc., Trenton, NJ.

Averill, L.J., 1974, The problem of being human, Judson Press, Valley Forge, PA.

Barret, P., 2000, Science \& theology since Copernicus: The search for understanding, Unisa Press, Pretoria.

Biko, S., 1978, I write what I like, The Bowerdean Press, London.

Billingsley, A., 1999, Mighty like a river: The Black church and social reform, Oxford University Press.

Bloem, J., Van Doorn, M., Duivestein, S., Excoffier, D., Maas, R. \& Van Ommeren, E., 2014, 'The fourth industrial revolution', Things Tighten 8, 11-15.

Boesak, A.A., 2004, 'Truth crushed to Earth will rise again, Christian Theology in South Africa - Looking back', in E.M. Conradie (ed.), African Theologies in Transformation, pp. 9-21, EFSA Institute, Cape Town.

Daneel, M.L., 1999, African earthkeepers environmental mission and liberation in Christian perspective, University of South Africa, Pretoria.

Doubrovski, E.L., Tsai, E.Y., Dikovsky, D., Geraedts, J.M., Herr, H. \& Oxman, N., 2015 'Voxel-based fabrication through material property mapping: A design method for bitmap printing', Computer-Aided Design 60, 3-13.
Ferrari, G.T., 2017, 'Design and the Fourth Industrial Revolution. Dangers and opportunities for a mutating discipline', The Design Journal 20(suppl. 1) S2625-S2633. https://doi.org/10.1080/14606925.2017.1352774

Fridman, L., 2018, Max Tegmark: Life 3.0 | MIT Artificial Intelligence (Al) Podcast, viewed n.d., from https://www.youtube.com/watch?v=Gi8LUnhP5yU\&list=PLYIvZ cNcC8pc4Ue_XFLjalQ51tH-uyG4a\&index $=22$.

Gillespie, M.E., 2008, The theological origins of modernity, University of Chicago Press, Chicago, IL.

Hensel, M. \& Menges, A., 2006, 'Differentiation and performance: multi-performance architectures and modulated environments', Architectural Design 76(2), 60-69. https://doi.org/10.1002/ad.241

Hlatshwayo, M., 2019, 'Debating the Fourth Industrial Revolution: First things first', New Agenda: South African Journal of Social and Economic Policy 2019(75), 26-29.

Kumar, K. \& Thakur, G.S.M., 2012, 'Advanced applications of neural networks and artificial intelligence: A review', IJ Information Technology and Computer Science 6, 57-68. https://doi.org/10.5815/ijitcs.2012.06.08

Mabasa, L., 1983, Policies of various organisations, pp. 117-169, Wits University, Johannesburg.

Mabasa, L., 1984, Forum for national unity, pp. 117-169, Wits University, Johannesburg..

Maimela, S.S., 2005, Systematic theology: Liberation theology STH415, UNISA, Pretoria.

Malcolm, X., 1964, 'The ballot or the bullet', April 3, pp. 23-44.

Maluleka, T., 2004, 'African religion as African religion, beyond the contextualisation paradigm', in E.M. Conradie (ed.), African theologies in transformation, pp. 184-190, EFSA Institute, Cape Town.

Maynard, A.D., 2015, 'Navigating the fourth industrial revolution', Nature Nanotechnology 10(12), 1005. https://doi.org/10.1038/nnano.2015.286

Oxman, N., 2010, 'Structuring materiality: Design fabrication of heterogeneous materials', Architectural Design 80(4), 78-85. https://doi.org/10.1002/ad.1110

Oxman N., 2013, 'Material ecology, in theories of the digital in architecture', in R. Oxman \& R. Oxman (eds.), pp. 1-7, Routledge, Taylor and Francis, London.

Oxman, N., 2016, 'Age of entanglement', Journal of Design and Science. https://doi. org/10.21428/7e0583ad

Prisecaru, P., 2016, 'Challenges of the fourth industrial revolution: Knowledge horizons', Economics 8(1), 57.

Rifkin, J., 2008, 'Leading the way to the third industrial revolution', European Energy Review 1, 1-36.

Rifkin, J., 2012, 'The third industrial revolution: How the internet, green electricity, and 3-d printing are ushering in a sustainable era of distributed capitalism', World Financial Review 1(1), 4052-4057.

Schwab, K., 2016, The fourth industrial revolution, World Economic Forum, Cologny/ Geneva.

Stewart, C.F., 1999, Black spirituality and black consciousness: Soul force, culture and freedom in the African-American experience, Africa World Press, Trenton, NY.

Tiro, A.O., 1972, Graduation speech by Onkgopotse Tiro at the University of the North, 29 April 1972, Mankweng.

Van Hooijdonk, R., Inspiration series: The future of energy, Richard Hooijdonk, n.p.

West, C., 1999, The Cornel West reader, Basic Civitas Books, New York, NY.

World Economic Forum, 2016, Africa 2016 - Africa's Fourth Industrial Revolution, viewed n.d., from https://www.youtube.com/watch?v=_CyByg5vXT8

Xing, B. \& Marwala, T., 2017, 'Implications of the fourth industrial age for higher education', The Thinker 73, 1-9. https://doi.org/10.25073/0866-773X/87 